\title{
Experimental study of the supercritical water oxidation process within the framework of solving the task of chemical production industrial water runoff treatment
}

\author{
Almaz Aetov ${ }^{1, *}$, Sergei Mazanov ${ }^{1}$, Zufar Zaripov ${ }^{1}$, and Farid Gumerov ${ }^{1}$ \\ ${ }^{1}$ Kazan National Research Technological University, Kazan, Russia
}

\begin{abstract}
The given paper presents results of an experimental study of the industrial water runoff oxidation within the propylene epoxidation process carried out under supercritical fluid conditions $(\mathrm{T}=653-723 \mathrm{~K}, \mathrm{P}=29-32$ $\mathrm{MPa}$ ) at a continuous operation installation using atmospheric oxygen as the oxidizing agent. Efficiency of the water runoff oxidation depending on the thermodynamic conditions of oxidation reaction was established. Solid residue elemental composition was determined.
\end{abstract}

\section{Introduction}

Modern world community is seriously concerned about the problems of natural resources depletion, and, particularly, of hydrocarbon raw materials reserves and of environmental pollution. Waste waters arising from the petroleum products processing, originating in pulp and paper industry and in other types of production activities are inflicting significant damage [1-3]. As a result of waste waters a water body, water transparency decreases, its color changes, suspended matters content increases, as well as the content of dry and dense residue, sulfates and chlorides, oxidability increases and the dissolved oxygen content decreases [4]. In order to reduce the negative impact of the waste water pollution on the environment, oxidative techniques are widely used. The given techniques are used in local installations in combination with further biological or profound waste water final treatment [5-9].

In addition, the role of catalytic processes in modern petrochemistry is important. In the case of using the homogeneous catalysts, there almost always appears a need in the reaction products separation and catalyst segregation in the form of a certain fraction followed by purification of a target component. Otherwise, the catalyst is irretrievably lost. Thus, the expensive molybdenum complex examined within the present work and used to accelerate the propylene epoxidation reaction acceleration in a multi-ton industrial process, after the reaction product washing is concentrated in waste water, which is subjected to thermal neutralization. As a result, the high cost molybdenum salts are lost being distributed in the flue gases and in the corresponding melt. Besides, economic expenditures are aggravated by

\footnotetext{
* Corresponding author: aetovalmaz@mail.ru
} 
environmental problems that arise. The above mentioned takes place and is due, first of all, to the lack of an efficient and cost-effective approach to separation of the molybdenum salts from the waste water. The above makes it relevant to search for a more efficient alternative method to treat the chemical industry waste waters in order to isolate and restore the spent homogeneous catalysts.

As an alternative way to solve this problem, it is proposed to use the supercritical fluid (SCF) media within the framework of combining the $\mathrm{CO} 2$ supercritical fluid extraction process and the supercritical water oxidation technique (SCWO). SCF simultaneously possess the properties of both liquid and gas. In other words, SCF is able to be compressed like gases (ordinary liquids are practically not compressible), and at the same time is able to dissolve solid substances, which is not characteristic for gases [10]. Solubility of both liquid and solid substances in the supercritical media is a function of pressure: the higher the pressure is, the higher is solubility of solid substances in supercritical media [11]. Processes under consideration are characterizes by high mass-exchanging characteristics with the short duration thereof, as well as by energy-saving and environmentally secure nature [12-14].

Speaking of the SCWO technique, we should mention that participating organic compositions and, in particular, waste water is oxidized (by oxygen, hydrogen peroxide, etc.) in the presence of water being in the supercritical state, up to obtaining process water, carbon dioxide and solid inorganic residue [15-18], which could contain chemical elements that possess high value in the market.

\section{Experimental part}

The water runoff under examination was the industrial water runoff resulting from the styrene and propylene oxide production process at the Nizhnekamskneftekhim PJSC and having the following composition:

- ethylbenzene $\mathrm{C} 6 \mathrm{H} 5 \mathrm{CH} 2 \mathrm{CH} 3-2.5 \%$ by weight;

- acetophenone $\mathrm{CH} 3 \mathrm{COC} 6 \mathrm{H} 5$ - 1\% by weight;

- methylphenylcarbinol (MPC) $\mathrm{C} 6 \mathrm{H} 5 \mathrm{CH}(\mathrm{OH}) \mathrm{CH} 3$ - $6.5 \%$ by weight;

- phenol $\mathrm{C} 6 \mathrm{H} 5 \mathrm{OH}-2.5 \%$ by weight;

- propylene glycol $\mathrm{C} 3 \mathrm{H} 8 \mathrm{O} 2$ - $12 \%$ by weight;

- Mo molybdenum (pure metal) - $0.2 \%$ by weight;

- $\mathrm{H}_{2} \mathrm{O}$ water- $40 \%$ by weight.

Within the framework of executing work on developing the process of waste water treatment under the reaction mixture SCF conditions, the original flow action experimental installation was used (Fig. 1). 


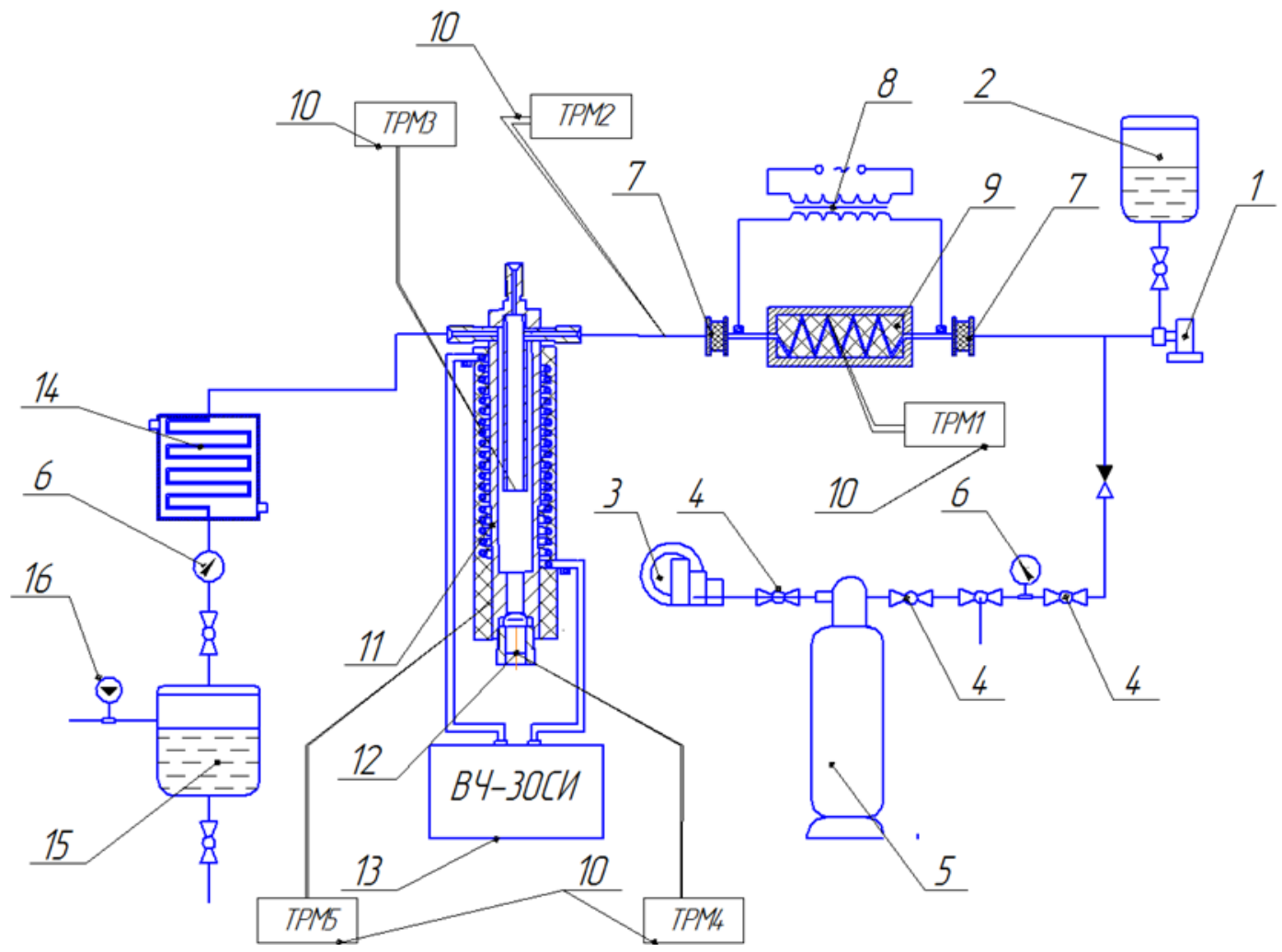

Fig. 1. SCWO flow installation schematic diagram: 1- high pressure pump; 2- initial waste water/air reservoir; 3- air compressor; 4- valve; 5- receiver; 6- gauge; 7- current isolating element; 8- step-down transformer; 9- heat exchanger for heating the feed mixture; 10- temperature sensor (thermocouple); 11- reactor; 12- residue collection chamber; 13- HF-30 high frequency induction heater; 14refrigerator; 15- treated waste water collection reservoir; 16-gas flow meter.

One of the main qualitative indicators of the potable, natural and waste water quality level could be chemical oxygen demand (COD or XПК, in Russian). Analysis of the COD product reaction in order to reduce this indicator was carried out using the photometric Expert-003ХПК COD Analyzer with a thermal reactor for 26 samples in accordance with GOST R 52708-2007 [19]. The COD measurement technique essence was to treat water samples with sulfuric acid and potassium bichromate at a given temperature in the presence of silver sulfate (oxidation catalyst) and mercury sulfate (II), used to reduce the effect of chlorides. The COD value in a given concentration range was determined by measuring the optical density of the tested solution at a given wavelength of 430 or $605 \mathrm{~nm}$ (depending on the measurement range) using calibration dependence of the solution optical density on the COD value.

$X$ oxidation efficiency was determined by the following formula:

$$
X=1-\frac{X \Pi K_{\kappa}}{X \Pi K_{H}}
$$

where: $\mathrm{X \Pi K_{ \textrm {H } }}$ is chemical oxygen consumption for the initial water runoff, $\mathrm{mgO}_{2} / 1$; $\mathrm{XПК}$ - value of chemical oxygen consumption for oxidized water runoff, $\mathrm{mgO}_{2} / \mathrm{l}$.

Surplus of the oxygen used was calculated by the following equation:

$$
O_{2}(\%)=\frac{\left[O_{2}\right]_{a}}{\left[O_{2}\right]_{s}} \times 100
$$


where: $\left[\mathrm{O}_{2}\right]_{\mathrm{a}}$ is actual concentration of oxygen supplied to the reactor, mmole/1; $\left[\mathrm{O}_{2}\right]_{\mathrm{s}}$ stoichiometric oxygen concentration based on the waste water COD, mmole/l.

The reaction product at the end of the water runoff oxidation process was extracted from the flow reactor and analyzed using the NexION 300D mass spectrometer.

Inorganic residue was subjected to analysis using the portable S1 TITAN X-ray phase analysis spectrometer.

\section{Results and discussion}

On the flow installation, the $5 \%$ water runoff was subjected to oxidation with a surplus of atmospheric oxygen of $100-400 \%$, in the temperature range of $\mathrm{T}=673-873 \mathrm{~K}$ and at pressure of $\mathrm{P}=25 \mathrm{MPa}$.

Table 1 presents results of the industrial runoff SCWO process experimental study.

Table 1. Industrial water runoff $(\mathrm{P}=25 \mathrm{MPa})$ oxidation reaction product $\mathrm{COD}\left(\mathrm{mgO}_{2} / \mathrm{l}\right)$

\begin{tabular}{|c|c|c|c|c|c|}
\hline $\mathrm{O}_{2}$ surplus, $\%$ & $\mathrm{~T}_{\text {reactor, }} \mathrm{K}$ & $\mathrm{COD}_{\text {av. }}, \mathrm{mgO}_{2} / 1$ & $\mathrm{O}_{2}$ surplus, $\%$ & $\mathrm{~T}_{\text {reactor, }}, \mathrm{K}$ & $\begin{array}{l}\mathrm{COD}_{\mathrm{av}}, \\
\mathrm{mgO}_{2} / 1\end{array}$ \\
\hline- & - & $67235^{*}$ & - & - & $67235^{*}$ \\
\hline \multirow{9}{*}{100} & 673 & 24650 & \multirow{9}{*}{300} & 673 & 16945 \\
\hline & 698 & 20445 & & 698 & 14480 \\
\hline & 723 & 17495 & & 723 & 13755 \\
\hline & 748 & 12285 & & 748 & 10220 \\
\hline & 773 & 9585 & & 773 & 8880 \\
\hline & 798 & 7510 & & 798 & 4440 \\
\hline & 823 & 5005 & & 823 & 2275 \\
\hline & 848 & 2170 & & 848 & 2085 \\
\hline & 873 & 1130 & & 873 & 895 \\
\hline \multirow{9}{*}{200} & 673 & 18770 & \multirow{9}{*}{400} & 673 & 12100 \\
\hline & 698 & 17175 & & 698 & 10435 \\
\hline & 723 & 15460 & & 723 & 9290 \\
\hline & 748 & 11275 & & 748 & 8815 \\
\hline & 773 & 9660 & & 773 & 4955 \\
\hline & 798 & 3985 & & 798 & 3035 \\
\hline & 823 & 3055 & & 823 & 2025 \\
\hline & 848 & 1920 & & 848 & 1140 \\
\hline & 873 & 1015 & & 873 & 715 \\
\hline
\end{tabular}

* initial solution

Based on the experimental data obtained (Table 1), the $X$ oxidation efficency was calculated (Figure 2): 


\section{EECE-2018}

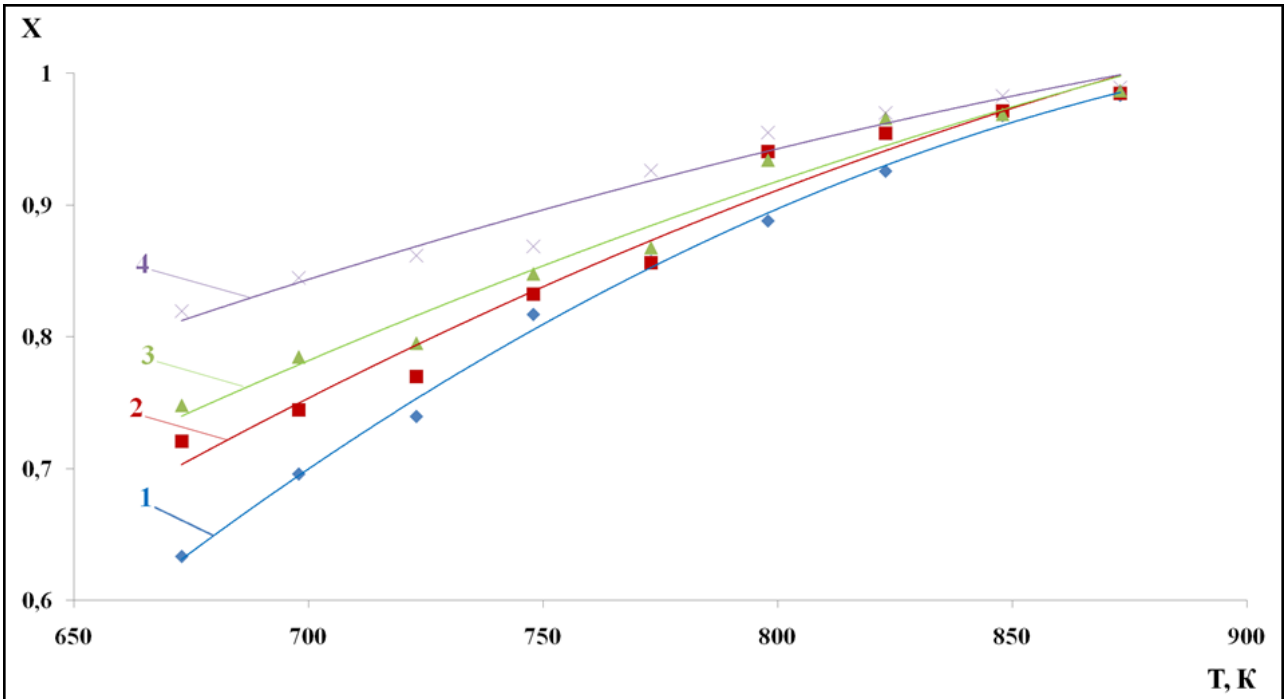

Fig. 2. Oxidation efficiency of industrial water runoff, carried out at $\mathrm{P}=25 \mathrm{MPa}$ and different oxygen surplus values: $1-100 \%, 2-200 \%, 3-300 \%, 4-400 \%$.

SCWO reaction is taking place with the efficiency of a process with maximum possible value of 0.98 , which is estimated relative to the COD value for the process water (allowable value for process water after waste water treatment is $\approx 1,000 \mathrm{mgO}_{2} / 1$ ).

An increase in temperature contributes to greater oxidation of waste water; however, despite the oxygen surplus, complete oxidation does not occur. The reason for this may be the presence of aromatic hydrocarbons in the residue composition. In the presence of a large amount of aromatic hydrocarbons, formation of resinous substances due to the predominance of radical reactions between aromatic fragments prevents the complete oxidation [20-22]. With increasing the pressure, the rate of radical reactions between aromatic fragments increases: and therefore, the oxidation rate significantly decreases. For the complete oxidation of aromatic compounds, significant increase in temperature or a decrease in the aromatic hydrocarbons concentration in the waste water due to the use of more diluted water runoff is required.

Tables 2 and 3 demonstrate the results of the residue (Table 2) and the SCWO reaction product (Table 3) mass spectrometer analysis.

Table 2. Dry residue components mass fractions

\begin{tabular}{|c|c|}
\hline Component & Content, $\%$ \\
\hline $\mathrm{Zn}$ & 38.822 \\
\hline $\mathrm{Fe}_{2} \mathrm{O}_{3}$ & 8.242 \\
\hline $\mathrm{Cr}$ & 2.934 \\
\hline $\mathbf{M o}$ & $\mathbf{2 . 2 6 6}$ \\
\hline $\mathrm{Ag}$ & 1.366 \\
\hline $\mathrm{Cu}$ & 0.854 \\
\hline $\mathrm{SiO}_{2}$ & 0.842 \\
\hline $\mathrm{Ni}_{2}$ & 0.809 \\
\hline $\mathrm{Al}_{2} \mathrm{O}_{3}$ & 0.641 \\
\hline $\mathrm{CaO}$ & 0.470 \\
\hline $\mathrm{Cl}$ & 0.269 \\
\hline $\mathrm{Ce}$ & 0.242 \\
\hline
\end{tabular}




\begin{tabular}{|c|c|}
\hline $\mathrm{Sn}$ & 0.227 \\
\hline $\mathrm{P}_{2} \mathrm{O}_{5}$ & 0.216 \\
\hline $\mathrm{TiO}_{2}$ & 0.206 \\
\hline $\mathrm{MnO}$ & 0.142 \\
\hline $\mathrm{K}_{2} \mathrm{O}$ & 0.091 \\
\hline $\mathrm{Sr}$ & 0.004 \\
\hline $\mathrm{Pb}$ & 0.003 \\
\hline
\end{tabular}

Metals from the table above are presented in a pure form. The molybdenum content was found to be insignificant $(2.27 \%)$, which is associated with large dilution $(5 \%)$ of the industrial water runoff.

The rest of the non-extracted molybdenum complex remained in the liquid fraction, which is clearly shown in Table 3.

Table 3. Molybdenum content in the liquid fraction

\begin{tabular}{|l|c|}
\hline \multicolumn{1}{|c|}{ Sample } & Mo, mg/l \\
\hline Water runoff sample taken in the runoff reservoir lower part & 3026.00 \\
\hline Water runoff sample taken in the runoff reservoir upper part & 2939.00 \\
\hline Treated water runoff $(\mathrm{T}=873 \mathrm{~K})$ & 11.98 \\
\hline
\end{tabular}

\section{Conclusion}

A study of the molybdenum-containing water runoffs supercritical water oxidation $(\mathrm{T}=673-$ $873 \mathrm{~K}, \mathrm{P}=25 \mathrm{MPa}$ ) process was carried out using atmospheric oxygen as an oxidizing agent in a flow-type installation. Significant decrease in the COD value of the reaction product in comparison with the COD of the initial water runoff was established. Entire water runoff oxidation to satisfy the requirements of the process water level $\left(\sim 1000 \mathrm{mgO}_{2} / \mathrm{l}\right)$ could be achieved by increasing temperature and oxygen surplus. In the obtained samples of the inorganic residue, presence of molybdenum was established, which is the target product for subsequent extraction.

The authors express their appreciation to the Russian Foundation for Basic Research (Agreement No. 18-29-06041_mk) for the financial support of the study.

\section{References}

1. V.A. Afanasiev, G.E. Zaikov, In the world of catalysis, (Science, Moscow, 1977)

2. S.E. Alekseev, thesis for the degree of Candidate of Technical Sciences, Research on the processes of ozonation for the intensification of cleaning $C B, 23 \mathrm{p}$ (2006)

3. O.N. Fedyaeva, A.A. Vostrikov, Russ. J. Phys. Chem. B 6, 844 (2012)

4. S.B. Rinehimer, Water Cond. Purif. 8 92-95 (1995)

5. E.S. Gayazova, R.A. Usmanov, F.M. Gumerov, S.V. Friedland, Z.I. Zaripov, F.R. Gabitov, R.Z. Musin, IJAMSC 1, 48-54 (2013)

6. X. Xiaowu, S. Shi-gun, Hefai Uniu. Sci. 3 (2005) 270-273

7. C. Jian-guo, L. Ai-min., Z. Quan-xing, Hefai Uniu. Sci. 3, 326-331 (2004)

8. J. Garcia-Gonzalez, M.J. Molina, F. Rodrigez, F. Mirada, J. Chem 46, 918-921 (2001)

9. F.M. Gumerov, A.N. Sabirzyanov, G.I. Gumerova, Sub-and supercritical fluids in polymer processing, 336p (2007) 
10. G.G. Elimanova, N.N. Batyrshin, A.A. Petukhov, Kh.E. Kharlampidi, Method for preparing soluble molybdenum catalyst.

11. L. Northcott, Molybdenum, in coll.: Molybdenum, trans. from English, ed. A.C. Nathanson, M., (1959)

12. Y.H. Shin, B. Veriansyah, E.-S. Song et al., Supercritical Water Oxidation of industrial Wastewaters, 8 International Symposium on Supercritical Fluids Kyoto (2006)

13. R. Usmanov, F. Shamsetdinov, R. Gabitov, Sh. Biktashev, F. Gumerov, Pilot plant for continuous transesterification of vegetable oils in the environment of supercritical ethanol and methanol, Supercritical Fluids: Theory and Practice 2, 1-19 (2011)

14. F. Gumerov, R. Kayumov, R. Usmanov, A.Sagdeev, I. Abdullin, AJAC 3, 950-957 (2012)

15. J.L. Hedrick, L.J. Mulcahey, L.T. Taylor. ACS Symp. Ser 15, 206-220 (1992)

16. G.T. Hong, The NaCl-Na2SO4-H2O system in supercritical water oxidation, In: Physical Chemistry of Aqueous Systems. Meeting the Needs of Industry, 565-572 (1995)

17. A.U. Aetov, R.A. Usmanov, R.R. Gabitov, S.V. Mazanov, M.S. Kurbangaleev, Bulletin of Kazan Technological University 19, 37-39 (2016)

18. F.H. Huang, M.H. Li, L.L. Lee, K.E. Starling, F.T. Chung, J. Chem. Eng. Japan 18, 490496 (1985)

19. F.M. Gumerov, R.A. Usmanov, A.U. Aetov, et al. Mass Spectrom. Purif. Tech. 3, 1-4 (2017)

20. R.A. Kayumov, A.A. Sagdeev, F.M. Gumerov, Disposal of molybdenum-containing waste using supercritical fluid media: monograph 144p (2016)

21. P.A. Webley, J.W. Tester, Supercritical Fluid Science and Technology, ACS Symp. Ser 406, 259-275 (1989)

22. C. Jiang, Q. Pan, Z. Pan, J. of Supercritical Fluids 12, 1-9 (1998) 